\title{
Long-Term Suicide Mortality Rates Decrease in Men and Increase in Women after the Niigata-Chuetsu Earthquake in Japan
}

\author{
Keiko Hyodo, ${ }^{1}$ Kazutoshi Nakamura, ${ }^{2}$ Mari Oyama, ${ }^{2}$ Osamu Yamazaki, ${ }^{3}$ \\ Izumi Nakagawa, ${ }^{4}$ Kazuo Ishigami, ${ }^{3}$ Yasuo Tsuchiya ${ }^{2}$ and Masaharu Yamamoto ${ }^{2}$ \\ ${ }^{1}$ School of Nursing, Faculty of Medicine, University of Miyazaki, Miyazaki, Japan \\ ${ }^{2}$ Department of Community Preventive Medicine, Niigata University Graduate School of Medical and Dental \\ Sciences, Niigata, Japan \\ ${ }^{3}$ Niigata Prefectural Government, Niigata, Japan \\ ${ }^{4}$ Department of Nursing, Social Welfare \& Psychology, Niigata Seiryo University, Niigata, Japan
}

\begin{abstract}
A devastating earthquake causes psychological distress, and may increase suicide mortality thereafter, yet previous studies have made inconsistent conclusions regarding this issue. The purpose of the present study was to determine whether the 2004 Niigata-Chuetsu earthquake in Japan affected long-term mortality from suicide. We conducted a comparative study of suicide mortality rates during the 5-year period preceding and the 3-year period following the earthquake in the disaster area and a control area in Niigata Prefecture, by analyzing death certificate data from October 1, 1999, to September 30, 2007. In men, baseline suicide mortality rates (5 years preceding the earthquake) were 48.4 per 100,000 person-years in the disaster area and 46.1 in the control area, and suicide mortality rates during the 3-year period following the earthquake were 46.0 and 45.1 , respectively. In women, baseline suicide mortality rates were 22.3 in the disaster area and 18.7 in the control area, and post-earthquake suicide mortality rates were 20.2 and 15.3 , respectively. In consequence, the decrease in suicide mortality rate during the 3 years postearthquake was significantly higher in the disaster area (2.5) than in the control area (1.0) $(p=0.0013)$ in men, whereas the decrease in suicide mortality rate was 2.1 in the disaster area and 3.0 in the control area $(p=0.1246)$ in women. We have concluded that the long-term mortality from suicide after the earthquake decreases in men and increases in women, suggesting that post-earthquake suicide mortality is sexdependent. Post-earthquake suicide prevention strategies should more aggressively target women.
\end{abstract}

Keywords: disasters/epidemiology/earthquakes/sex/mortality/suicide

Tohoku J. Exp. Med., 2010, 220 (2), 149-155. (C) 2010 Tohoku University Medical Press

A large earthquake, with a near-epicenter maximum seismic intensity of 7 on the Japan Meteorological Agency's intensity scale, jolted mid-Niigata Prefecture (Chuetsu region) on October 23, 2004. The Niigata-Chuetsu earthquake caused a great deal of damage, leaving 68 dead and 121,495 homes destroyed (Niigata Prefectural Government 2008). The earthquake occurred in a rural, mountainous area and caused significant ground disaster leading to traffic and communication network disruptions. The socioeconomic loss as a result of the earthquake was estimated at 3 trillion yen (30 billion dollars) (Tatano et al. 2005).

A devastating earthquake and the unfavorable aftermath that follows cause psychological distress in those affected by the earthquake (Bourque et al. 2002; Kiliç and Ulusoy 2003; Chou et al. 2007). The Niigata-Chuetsu earthquake was no exception (Toyabe et al. 2006) and an increased mortality from suicide in the disaster areas was anticipated. However, findings from previous studies on changes in suicide mortality after earthquakes have varied widely and are often contradictory to other similar studies. Krug et al. (1998) demonstrated that suicide rates increased after severe earthquakes in the United States, and the 1999 Taiwan earthquake also yielded similar results (Yang et al. 2005; Yip 2009). On the other hand, reports from the Northridge and Hanshin-Awaji earthquakes showed that suicide rates did not increase, but rather decreased after the earthquakes (Shioiri et al. 1999; Shoaf et al. 2004; Nishio et al. 2009). Therefore, further studies are needed to address this issue.

Psychological problems induced by damage and loss from an earthquake are considered to have long-lasting effects (Murphy 1986; Kiliç and Ulusoy 2003). In the case of the Niigata-Chuetsu earthquake, community reconstruction was delayed due to massive ground destruction in rural areas. We therefore hypothesized that an earthquake of this magnitude may increase long-term mortality due to suicide.

Received December 1, 2009; revision accepted for publication December 24, 2009. doi:10.1620/tjem.220.149

Correspondence: Kazutoshi Nakamura, M.D., Department of Community Preventive Medicine, Niigata University, 1-757 Asahimachi-

dori, Niigata City 951-8518, Japan.

e-mail: kazun@med.niigata-u.ac.jp 
The aim of this study was to determine how the NiigataChuetsu earthquake affected suicide mortality 3 years after the earthquake.

\section{Subjects and Methods}

The 2004 Niigata-Chuetsu earthquake occurred at 17:56 on October 23. The epicenter was located at 37 degrees latitude, 29 minutes North, and 138 degrees longitude, 87 minutes East (Fig. 1), registering M6.8 on the Richter scale. The disaster area was defined as the Chuetsu region composed of 12 municipalities: Nagaoka, Ojiya, Tokamachi, Kashiwazaki, Mitsuke, Uonuma, Minamiuonuma, Kawaguchi, Yuzawa, Tsunan, Izumozaki, and Kariwa (Fig. 1). Data on short-term casualties and destroyed houses in the disaster area are shown in Table 1 (Niigata Prefectural Government 2008). Damage to some municipalities, namely Yuzawa and Tsunan, was light. However, due to the impact of close socioeconomic ties between these towns and other communities in Chuetsu where damage was more severe, we included the two towns in the disaster area. All other municipalities outside the disaster area in Niigata Prefecture were defined as the control area (total population 1,776,033). The proportion of the 2004 population aged 65 years and older was $24.6 \%$ in the disaster and $22.9 \%$ in the control areas, and the rate of aging was similar in the two areas after the earthquake (Nakagawa et al. 2009). This study was approved by the Ethics Committee of Niigata University School of Medicine (No. 864).

We examined death certificates of all suicide decedents (ICD-10, X60-84) in Niigata Prefecture between October 1, 1999, and September 30, 2007, which reflects a period from 5 years before until 3 years after the earthquake (October 2004). In this study, baseline death rate was defined as death rate during the 5 years before the earthquake. We obtained approval of this definition from the Japanese government prior to obtaining data from death certificates. Data were provided by the Ministry of Health, Labour, and Welfare (No. 0819001) and the Ministry of Internal Affairs and Communications (No. 272) with official permission, after each person's name, address, and other forms of identification were deleted. The data set included date of death, cause of death, sex, and area code.

Information on the overall population, as the denominator in calculating death rates, was obtained from the Annual Reports of Niigata Prefectural Health and Social Welfare published in 2000 2008 (Niigata Prefectural Government 2000 - 2008). As the earthquake occurred in October 2004, we defined the first year after the earthquake as the period from October 2004 to September 2005. The average population of the first year was calculated as an average of the October 1st populations of 2004 and 2005, given that Japan publishes the yearly population on the first day of October. The yearly populations of the remaining years were calculated in the same way.

The chi-square test was used to assess the difference in death rates before and after the earthquake. Differences in suicide deaths in the disaster and control areas during the 3 years (October 2004 September 2007) after the earthquake were tested as follows: (1) We calculated the expected number of suicide deaths during the 3 years in the disaster and control areas by multiplying total person-years for the 3 years by the suicide death rate during the baseline 5 years (October 1999 - September 2004) before the earthquake. (2) Differences in the expected and actual number of suicide deaths during the 3 years in the disaster and control areas were then compared using the chi-square test. Secular trends in suicide death rate were assessed by the Cochran-Armitage test. SAS statistical software (release 9.1.3) was used to conduct all statistical analyses and a p-value less than 0.05 was considered statistically significant.

\section{Results}

Baseline death rates from suicide ( 5 years before the earthquake) in Niigata Prefecture were 46.8 per 100,000 person-years in men, 19.7 per 100,000 person-years in women, and 32.8 per 100,000 person-years in total. Secular trends in death rates from suicide in the disaster and control areas from October 1999 to September 2007 are shown in Fig. 2. In men, the death rate in the disaster area was higher
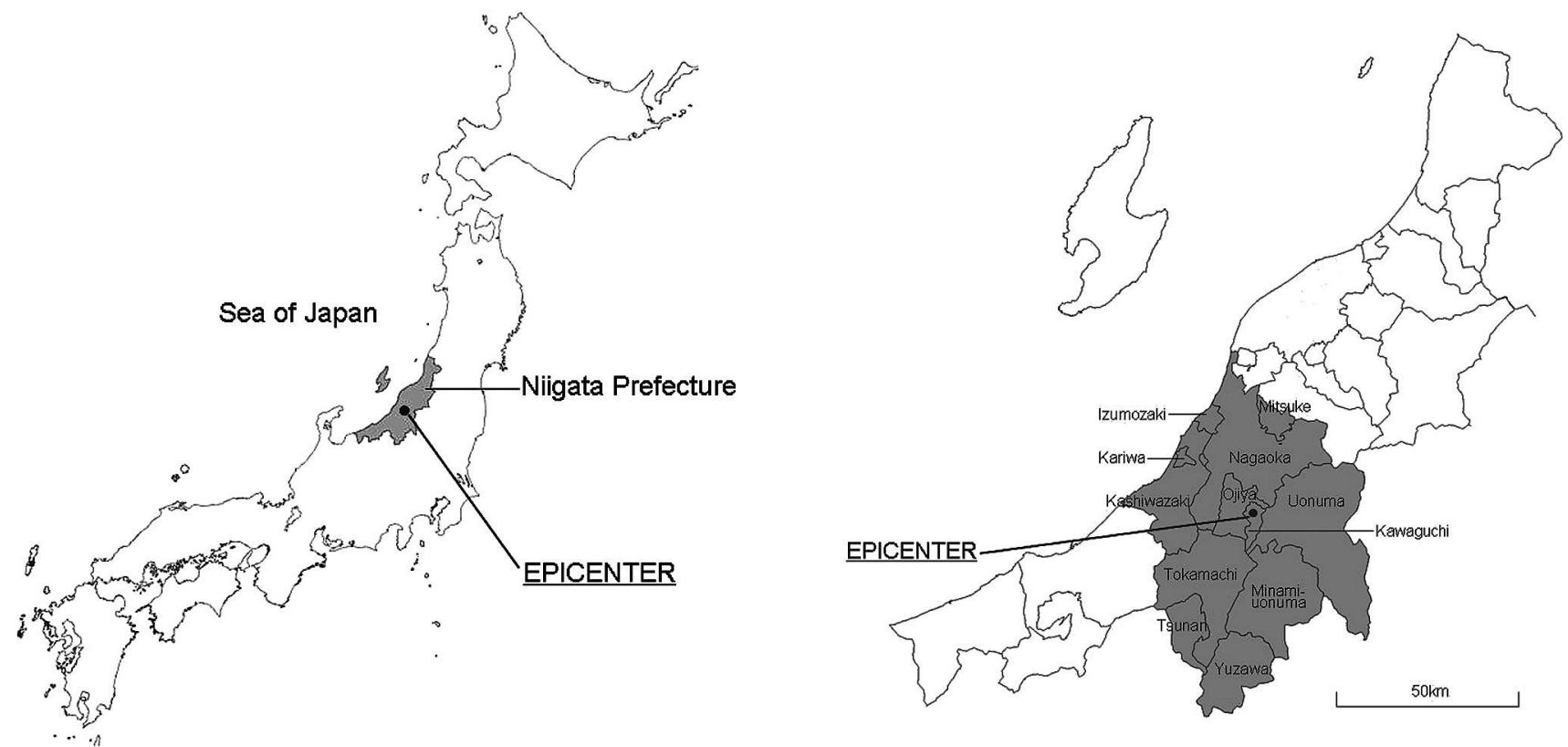

Fig. 1. The epicenter and disaster area of the Niigata-Chuetsu earthquake in Niigata Prefecture, Japan. 
Table 1. Short-term casualties and destroyed homes in disaster areas (12 municipalities) and control area following the Niigata-Chuetsu earthquake.

\begin{tabular}{|c|c|c|c|c|c|}
\hline & $\begin{array}{c}\text { Population } \\
\text { in October } 2004\end{array}$ & $\begin{array}{l}\text { Death rate } \\
(/ 100,000)\end{array}$ & $\begin{array}{c}\text { Rate of } \\
\text { wounded } \\
(/ 100,000)\end{array}$ & $\begin{array}{l}\text { Half-completely } \\
\text { destroyed homes } \\
\text { (/1,000 household) }\end{array}$ & $\begin{array}{c}\text { Partially }(<1 / 2) \\
\text { destroyed homes } \\
(/ 1,000 \text { household })\end{array}$ \\
\hline Nagaoka City & 285,104 & 7.7 & 833 & 103 & 691 \\
\hline Ojiya City & 40,570 & 46.8 & 1,935 & 281 & 727 \\
\hline Tokamachi City & 62,851 & 14.3 & 942 & 236 & 690 \\
\hline Kashiwazaki City & 95,852 & 0 & 75 & 12 & 167 \\
\hline Mitsuke City & 43,123 & 7.0 & 1,192 & 46 & 721 \\
\hline Uonuma City & 43,973 & 11.4 & 719 & 35 & 369 \\
\hline Minamiuonuma City & 63,930 & 1.6 & 41 & 1 & 128 \\
\hline Kawaguchi Town & 5,530 & 108.5 & 1,121 & 722 & 282 \\
\hline Yuzawa Town & 8,890 & 11.2 & 11 & 0 & 0 \\
\hline Tsunan Town & 11,885 & 0 & 109 & 0.3 & 63 \\
\hline Izumozaki Town & 5,423 & 0 & 18 & 4 & 54 \\
\hline Kariwa Village & 4,861 & 0 & 165 & 133 & 560 \\
\hline Disaster area (Total) & 671,992 & 9.8 & 709 & 96 & 516 \\
\hline Control area* & $1,776,033$ & 0.1 & 2 & 0.1 & 2 \\
\hline
\end{tabular}

*The other areas in Niigata Prefecture.

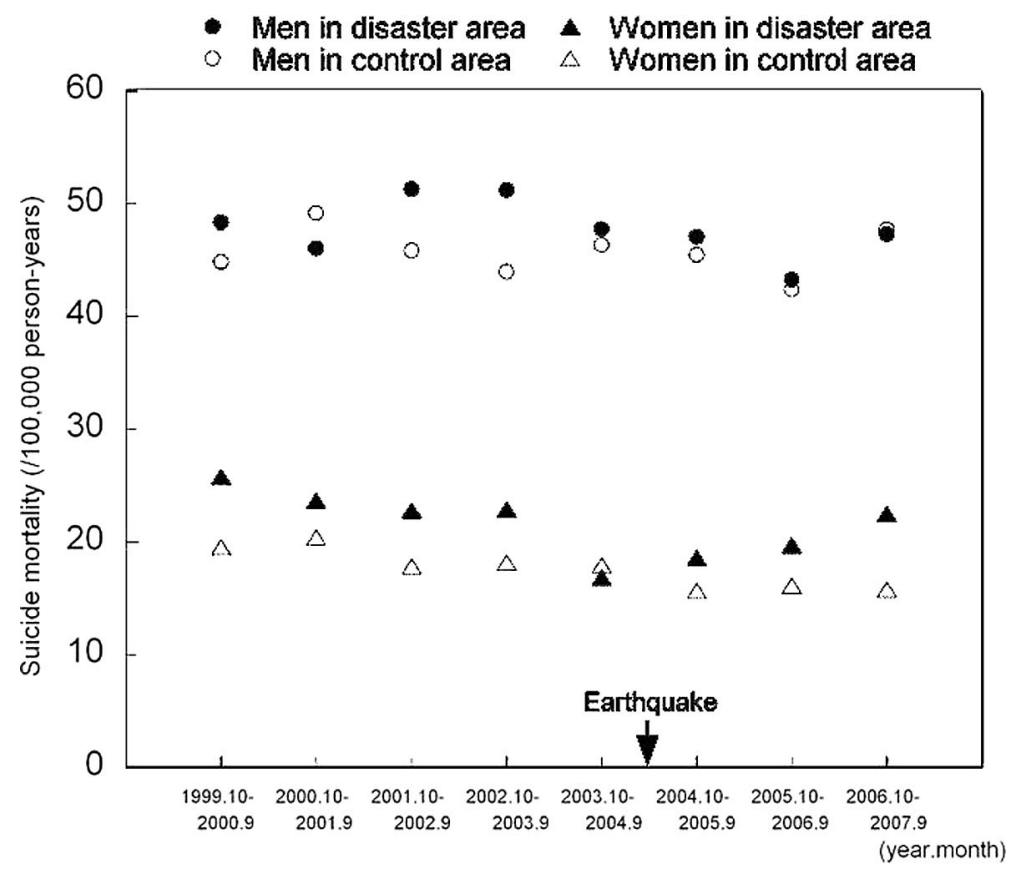

Fig. 2. Secular trends in suicide mortality in the disaster and control areas by sex. Post-earthquake suicide death rates in the disaster appear to increase in women.

than that in the control area except for the 1-year period (October 2000 - September 2001) during the baseline 5 years before the earthquake, and no upward or downward trend was found throughout the observed period. In women, the death rate in the disaster area was also higher than that in the control area except for the 1-year period (October 2003 - September 2004) during the baseline 5-year period before the earthquake, and there was a downward trend in both the disaster $(p=0.0245)$ and control areas $(p=0.0887$, borderline significance). In women, we observed a downward trend during the baseline 5-year period and an upward trend ( $p=0.0937$, borderline significance) after the earthquake in the disaster area, and a downward trend ( $p=$ $0.0008)$ throughout the observed period in the control area.

Death rates from suicide during the 5 years before and 3 years after the earthquake in the disaster and control areas are shown in Table 2. In men, death rates during the 3 years after the earthquake decreased both in the disaster and con- 
trol areas, but were not significantly different to that before the earthquake. The same pattern was also observed in women, but this difference was significant in the control area. Overall findings among men and women were similar.

A comparison of death rates from suicide after the earthquake between the disaster and control areas is shown in Table 3, where the decrease in actual minus expected numbers of deaths was determined. In men, the decrease in expected minus actual numbers of deaths in the disaster area was significantly larger than in the control area. In women, the decrease in the disaster area was smaller than that in the control area, but these decreases were not significantly different by area. Overall decreases were similar in both disaster and control areas.

\section{Discussion}

The major finding of the present study is that suicide death rates in the disaster area decreased among men and increased among women during the 3-year period after the Niigata-Chuetsu earthquake in comparison to the control area, suggesting a sex difference in post-earthquake suicide mortality. In men, there was no difference in suicide death rates before and after the earthquake in both disaster and control areas (Table 2); however, there was a significant difference in the extent of decrease in suicide death numbers between the disaster and control areas (Table 3 ). Specifically, the difference in post-earthquake decrease in female suicide death rates between the disaster and control areas was not significant ( $p=0.1246$ in Table 3 ). However, a comparison of secular trends in female suicide death rates between the disaster and control areas (Fig. 2) showed different suicide trends after the earthquake. This suggested a post-earthquake increase in the female suicide death rate.

Some epidemiologic studies support increased suicide mortality after large earthquakes. Krug et al. (1998) showed increased suicide rates after earthquakes in four counties in the United States ( $+19.7 \%$ on average), although no information on sex differences was indicated. The 1999 earthquake in Taiwan reported an interesting finding with respect to sex differences in post-earthquake suicide (Yip 2009). The study demonstrated that the female suicide rate doubled after the earthquake, whereas the increase in suicide rate among men was relatively small, suggesting a sex difference.

Other epidemiologic studies have supported no change or even a decrease in suicide mortality after large earthquakes. Shoaf et al. (2004) reported that the 1994 Northridge earthquake in California did not increase suicide rates and suggested some ethnic differences. A study of the 1995 Great Hanshin-Awaji earthquake in Japan, which is

Table 2. A comparison of suicide death rates before (1999.10 - 2004.9) and after (2004.10 - 2007.9) the Niigata-Chuetsu earthquake on October 23, 2004, by area and gender.

\begin{tabular}{|c|c|c|c|c|c|c|}
\hline & \multicolumn{3}{|c|}{ Disaster area* } & \multicolumn{3}{|c|}{ 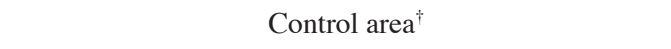 } \\
\hline & $\begin{array}{c}\text { Before } \\
\text { the earthquake } \\
1999.10-2004.9\end{array}$ & $\begin{array}{c}\text { After } \\
\text { the earthquake } \\
2004.10-2007.9\end{array}$ & $\begin{array}{l}\text { Chi-square test } \\
\text { for difference }\end{array}$ & $\begin{array}{c}\text { Before } \\
\text { the earthquake } \\
1999.10-2004.9\end{array}$ & $\begin{array}{c}\text { After } \\
\text { the earthquake } \\
2004.10-2007.9\end{array}$ & $\begin{array}{l}\text { Chi-square test } \\
\text { for difference }\end{array}$ \\
\hline \multicolumn{7}{|l|}{ Male } \\
\hline Number of deaths & 804 & 447 & $\begin{array}{l}\text { chi-square }=0.76 \\
p=0.3848\end{array}$ & 1,994 & 1,151 & $\begin{array}{l}\text { chi-square }=0.36 \\
p=0.5495\end{array}$ \\
\hline $\begin{array}{l}\text { Population } \\
\text { (person-years) }\end{array}$ & $1,662,025$ & 972,663 & & $4,321,693$ & $2,550,512$ & \\
\hline $\begin{array}{l}\text { Death rate } \\
\text { (per } 100,000 \text { person-years) }\end{array}$ & 48.4 & 46.0 & $\begin{array}{l}\text { Change, }-2.4 \\
(-5.0 \%)\end{array}$ & 46.1 & 45.1 & $\begin{array}{l}\text { Change, }-1.0 \\
(-2.2 \%)\end{array}$ \\
\hline \multicolumn{7}{|l|}{ Female } \\
\hline Number of deaths & 387 & 206 & $\begin{array}{l}\text { chi-square }=1.22, \\
p=0.2686\end{array}$ & 862 & 430 & $\begin{array}{l}\text { chi-square }=8.72, \\
p=0.0031\end{array}$ \\
\hline $\begin{array}{l}\text { Population } \\
\text { (person-years) }\end{array}$ & $1,739,232$ & $1,018,446$ & & $4,610,479$ & $2,737,455$ & \\
\hline $\begin{array}{l}\text { Death rate } \\
\text { (per } 100,000 \text { person-years) }\end{array}$ & 22.3 & 20.2 & $\begin{array}{l}\text { Change, }-2.1 \\
(-9.4 \%)\end{array}$ & 18.7 & 15.7 & $\begin{array}{l}\text { Change, }-3.0 \\
(-16.0 \%)\end{array}$ \\
\hline \multicolumn{7}{|l|}{ Total } \\
\hline Number of deaths & 1,191 & 653 & $\begin{array}{l}\text { chi-square }=1.81 \\
p=0.1784\end{array}$ & 2,856 & 1,581 & $\begin{array}{l}\text { chi-square }=4.59, \\
p=0.0322\end{array}$ \\
\hline $\begin{array}{l}\text { Population } \\
\text { (person-years) }\end{array}$ & $3,401,257$ & $1,991,109$ & & $8,932,172$ & $5,287,967$ & \\
\hline $\begin{array}{l}\text { Death rate } \\
\text { (per } 100,000 \text { person-years) }\end{array}$ & 35.0 & 32.8 & $\begin{array}{l}\text { Change, }-2.2 \\
(-6.3 \%)\end{array}$ & 32.0 & 29.9 & $\begin{array}{l}\text { Change, }-2.1 \\
(-6.6 \%)\end{array}$ \\
\hline
\end{tabular}

*Chuetsu area, including Nagaoka, Kashiwazaki, Ojiya, Tokamachi, Mitsuke, Uonuma, Minamiuonuma, Kawaguchi, Yuzawa, Tsunan, Izumozaki, and Kariwa, in Niigata Prefecture.

Other areas in Niigata Prefecture. 
Table 3. Differences in suicide deaths between the disaster* and control ${ }^{\dagger}$ areas during the 3 years $(2004.10-2007.9)$ after the Niigata-Chuetsu earthquake on October 23, 2004, by gender.

\begin{tabular}{|c|c|c|c|c|}
\hline & \multicolumn{3}{|c|}{ Deaths from suicide 3 years after the earthquake (2004.10 - 2007.9) } & \multirow{2}{*}{$\begin{array}{l}\text { Chi-square test for } \\
\text { difference in the decrease } \\
\text { between the two areas }\end{array}$} \\
\hline & $\begin{array}{l}\text { Expected } \\
\text { number }\end{array}$ & $\begin{array}{l}\text { Actual } \\
\text { number }\end{array}$ & Decrease in number (Expected - Actual) & \\
\hline \multicolumn{5}{|l|}{ Male } \\
\hline Disaster area* & 471 & 447 & 24 per 972,663 person-years ( 2.5 per 100,000 person-years) & \\
\hline Control area ${ }^{\dagger}$ & 1,177 & 1,151 & 26 per $2,550,512$ person-years ( 1.0 per 100,000 person-years) & chi-square $=10.4, p=0.0013$ \\
\hline \multicolumn{5}{|l|}{ Female } \\
\hline Disaster area* & 227 & 206 & 21 per $1,018,446$ person-years ( 2.1 per 100,000 person-years) & \\
\hline Control area $^{\dagger}$ & 512 & 430 & 82 per $2,737,455$ person-years ( 3.0 per 100,000 person-years) & chi-square $=2.36, p=0.1246$ \\
\hline \multicolumn{5}{|l|}{ Total } \\
\hline Disaster area* & 697 & 653 & 44 per $1,991,109$ person-years ( 2.2 per 100,000 person-years) & \\
\hline Control area ${ }^{\dagger}$ & 1,691 & 1,581 & 110 per $5,287,967$ person-years ( 2.1 per 100,000 person-years) & chi-square $=0.11, p=0.7347$ \\
\hline
\end{tabular}

*Chuetsu region, including Nagaoka, Kashiwazaki, Ojiya, Tokamachi, Mitsuke, Uonuma, Minamiuonuma, Kawaguchi, Yuzawa, Tsunan, Izumozaki, and Kariwa, in Niigata Prefecture.

Other areas in Niigata Prefecture.

*Calculated based on mortality from suicide 5 years before the earthquake (1999.10 - 2004.9).

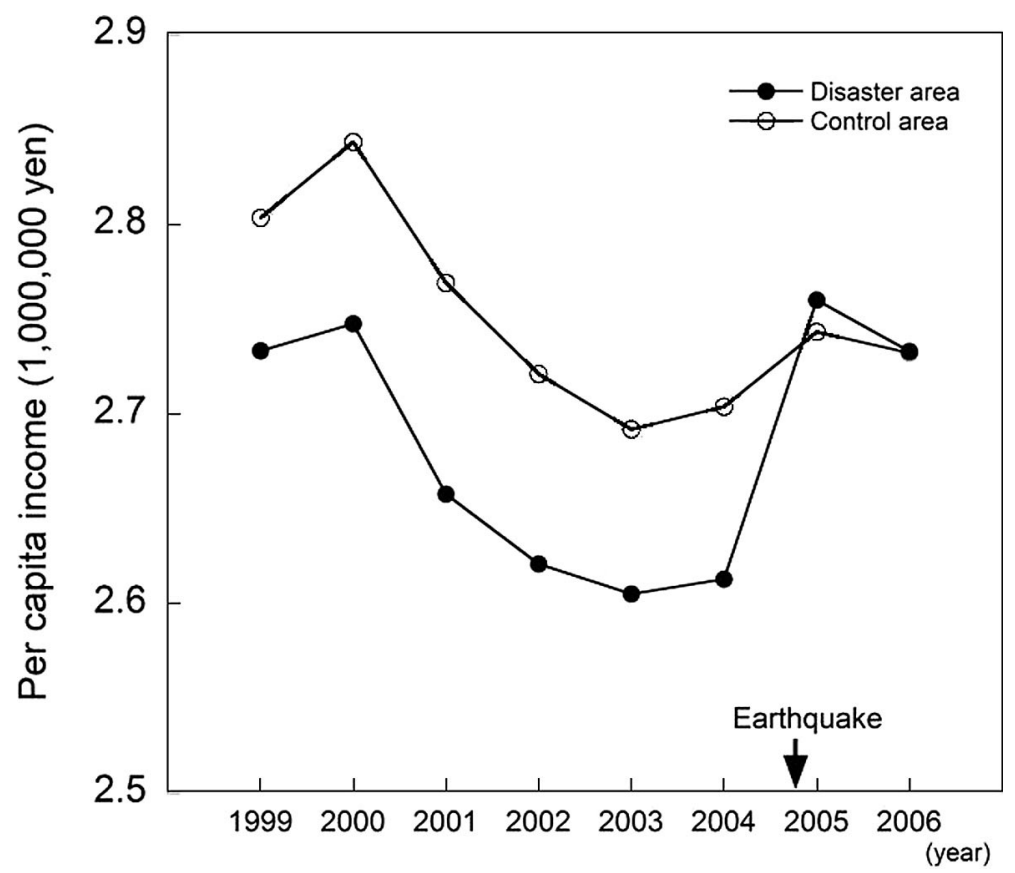

Fig. 3. Trends in per capita income in the disaster and control areas. After the Niigata-Chuetsu earthquake, the economical status in the disaster areas improved due to temporary financial aid from the government.

comparable to the present study in terms of ethnicity and seismic intensity, showed decreased suicide rates, especially in men, 2 years after the earthquake (Shioiri et al. 1999; Nishio et al. 2009). The results from the Great HanshinAwaji earthquake were similar to the results among men in the present study. Shioiri et al. (1999) interpreted the decrease in male suicide rates after the Hanshin-Awaji earthquake as a result of major societal upheaval. A decrease in suicide rate after earthquakes has been reported only in Japanese men, which may be explained by cultural differences. Japan has one of the highest suicide rates in the world; in the last decade, there were more than 30,000 suicides annually, $70 \%$ of which were men (McCurry 2008). Japanese men are believed to commit suicide due to jobrelated or financial problems (Crump 2006).

Yamasaki et al. (2005) reported that poor socioeconomic factors, such as low income or unemployment, are important determinants of suicide rates among Japanese men. After the Niigata-Chuetsu earthquake, the economical status in the disaster areas improved due to temporary financial aid from the government (Statistics Division, Department of General Affairs and Management, Niigata 
Prefecture 2009) as shown in Fig. 3, which illustrates the per capita income in the disaster and control areas. This may partly be associated with the decrease in mortality rate among men in the disaster area compared to that in the control area.

In contrast, post-earthquake suicide rates in women in the disaster area tend to increase relative to the control area. The reason for this increase is unclear. Kuwabara et al. (2008) investigated factors impacting psychological distress after the Niigata-Chuetsu earthquake, and found that women had higher levels of psychological distress and more psychiatric disorders than men. This finding supports the increase in suicide mortality among women after the earthquake observed in the present study. In addition, Yip (2009) reported a sex difference in post-earthquake suicide rates in the 1999 Taiwan earthquake, such that suicide rates in women increased more rapidly than did that in men. Yip (2009) added that male suicide rates increased when the earthquake's impact on the local economy was fully manifested, and the sex difference disappeared 2 years later. If this is the case, the sex difference in post-earthquake suicide rates may be a transient phenomenon.

The present study has strength. Since the boundary of Niigata Prefecture is surrounded by high mountains, changes in the population are relatively small; the average population change within the disaster area was $3.2 \%$ in $2004,3.1 \%$ in $2005,2.9 \%$ in 2006 , and $2.8 \%$ in 2007 , compared to $3.2 \%$, $2.9 \%, 2.7 \%$, and, $2.9 \%$, respectively, in the control area (Niigata Prefectural Government 2000 - 2008).

The present study has several important limitations. Physical damage and financial loss varied among subregions within a municipality in the disaster area, but we were unable to obtain detailed data on either damage/loss or the number of suicide deaths in such sub-regions. The effects of the Niigata-Chuetsu earthquake on suicide mortality rates may have been larger for people living in subregions where damage/loss was serious. Finally, the effects of the Niigata-Chuetsu earthquake on suicide mortality rates may simply be due to chance and should be reassessed in other earthquake settings.

The sex difference in post-earthquake suicide mortality rates observed in the present study has important implications. The present study suggests that women in the disaster area had increased suicide mortality rates after the earthquake compared to women in the control area, and thus policymakers in public health should be aware of the need for long-term suicide prevention after an earthquake. It should be noted that under normal circumstances, women represent a low risk group for suicide and a much lower risk group than men in the present study. Considering this fact, we surmise that in general, people who are normally at a low risk for suicide become a high risk group when a large earthquake occurs.

The present study demonstrated a sex difference in suicide mortality rates 3 years after a major earthquake. Preventive strategies against post-earthquake suicide should more readily target women. People in the disaster areas are still struggling to reconstruct their lives due to financial loss, and thus further studies should clarify how long these changes in suicide mortality rates in both men and women will endure.

\section{References}

Bourque, L.B., Siegel, J.M. \& Shoaf, K.I. (2002) Psychological distress following urban earthquakes in California. Prehosp. Disaster Med., 17, 81-90.

Chou, F.H., Wu, H.C., Chou, P., Su, C.Y., Tsai, K.Y., Chao, S.S., Chen, M.C., Su, T.T., Sun, W.J. \& Ou-Yang, W.C. (2007) Epidemiologic psychiatric studies on post-disaster impact among Chi-Chi earthquake survivors in Yu-Chi, Taiwan. Psychiatry Clin. Neurosci., 61, 370-378.

Crump, A. (2006) Suicide in Japan. Lancet, 367, 1143.

Kiliç, C. \& Ulusoy, M. (2003) Psychological effects of the November 1999 earthquake in Turkey: an epidemiological study. Acta Psychiatr. Scand., 108, 232-238.

Krug, E.G., Kresnow, M., Peddicord, J.P., Dahlberg, L.L., Powell, K.E., Crosby, A.E. \& Annest, J.L. (1998) Suicide after natural disasters. N. Engl. J. Med., 338, 373-378.

Kuwabara, H., Shioiri, T., Toyabe, S., Kawamura, T., Koizumi, M., Ito-Sawamura, M., Akazawa, K. \& Someya, T. (2008) Factors impacting on psychological distress and recovery after the 2004 Niigata-Chuetsu earthquake, Japan: community-based study. Psychiatry Clin. Neurosci., 62, 503-507.

McCurry, J. (2008) Japan to rethink suicide-prevention policies. Lancet, 371, 2071

Murphy, S.A. (1986) Status of natural disaster victims' health and recovery 1 and 3 years later. Res. Nurs. Health, 9, 331-340.

Nakagawa, I., Nakamura, K., Oyama, M., Yamazaki, O., Ishigami, K., Tsuchiya, Y. \& Yamamoto, M. (2009) Long-term effects of the Niigata-Chuetsu earthquake in Japan on acute myocardial infarction mortality: an analysis of death certificate data. Heart, 95, 2009-2013.

Niigata Prefectural Government. (2000-2008) Annual Reports of Niigata Prefectural Health and Social Welfare, Niigata Prefectural Government, Niigata, Japan. (in Japanese)

Niigata Prefectural Government. (2008) Niigata Prefecture Report on Damage in the 2004 Niigata-Chuetsu Earthquake (No. 173), Niigata Prefectural Government, Niigata, Japan. (in Japanese)

Nishio, A., Akazawa, K., Shibuya, F., Abe, R., Nushida, H., Ueno, Y., Nishimura, A. \& Shioiri, T. (2009) Influence on the suicide rate two years after a devastating disaster: a report from the 1995 Great Hanshin-Awaji Earthquake. Psychiatry Clin. Neurosci., 63, 247-250.

Shioiri, T., Nishimura, A., Nushida, H., Tatsuno, Y. \& Tang, S.W. (1999) The Kobe earthquake and reduced suicide rate in Japanese males. Arch. Gen. Psychiatry, 56, 282-283.

Shoaf, K., Sauter, C., Bourque, L.B., Giangreco, C. \& Weiss, B. (2004) Suicides in Los Angeles County in relation to the Northridge earthquake. Prehosp. Disaster Med., 19, 307-310.

Statistics Division, Department of General Affairs and Management, Niigata Prefecture. (2009) Economic Accounts of Municipalities of Niigata Prefecture, 2008, Statistics Division, Department of General Affairs and Management, Niigata Prefecture, Niigata, Japan. (in Japanese)

Tatano, H., Kajitani, Y. \& Tsuchiya, S. (2005) Socio-economic effects of Niigata Chuetsu earthquake. Ann. Disast. Prev. Res. Inst. Kyoto Univ., 48A, 191-201. (in Japanese)

Toyabe, S., Shioiri, T., Kuwabara, H., Endoh, T., Tanabe, N., Someya, T. \& Akazawa, K. (2006) Impaired psychological recovery in the elderly after the Niigata-Chuetsu Earthquake in Japan: a population-based study. BMC Public Health, 6, 230.

Yamasaki, A., Sakai, R. \& Shirakawa, T. (2005) Low income, 
unemployment, and suicide mortality rates for middle-age persons in Japan. Psychol. Rep., 96, 337-348.

Yang, C.H., Xirasagar, S., Chung, H.C., Huang, Y.T. \& Lin, H.C. (2005) Suicide trends following the Taiwan earthquake of
1999: empirical evidence and policy implications. Acta Psychiatr. Scand., 112, 442-448.

Yip, P. (2009) Effects of an earthquake on suicide rates in Nantou, Taiwan. Br. J. Psychiatry, 194, 190. 